\title{
JOGOS E BRINCADEIRAS: TEMPOS, ESPAÇOS E DIVERSIDADE
}

\author{
GAMES AND PLAYS: TIMES, SPACES AND DIVERSITY
}

\section{JUEGOS Y DIVERSIONES: TIEMPOS, ESPACIOS Y DIVERSIDAD}

KISHIMOTO, T. M.; SANTOS, M. W. dos. (org.). Jogos e Brincadeiras: tempos, espaços e diversidade. São Paulo: Cortez, 2016, 263 p.

\section{Ubirajara da Silva Caetano ${ }^{\mathrm{I}}$ \\ Marineide de Oliveira Gomes ${ }^{\mathrm{II}}$}

${ }^{\text {I } U n i v e r s i d a d e ~ C a t o ́ l i c a ~ d e ~ S a n t o s, ~ S a ̃ o ~ P a u l o ~-~ B r a s i l . ~ E-m a i l: ~ q u e s t 2742 @ g m a i l . c o m . ~ O R C I D: ~}$ https://orcid.org/0000-0002-7391-6453

II Universidade Católica de Santos, São Paulo - Brasil. E-mail: marineine.gomes@unisantos.br. ORCID: https://orcid.org/0000-0002-2929-4888

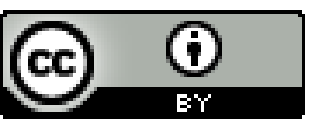

Educação: Teoria e Prática, Rio Claro, SP, Brasil - eISSN: 1981-8106

Está licenciada sob Licença Creative Common

A resenha objetiva apresentar o livro, destacando aspectos importantes dos jogos e brincadeiras no contexto da educação, pela promoção do diálogo com realidades históricoculturais distintas, apresentando-se como leitura indispensável para estudiosos e 
pesquisadores da área e, sobretudo, para a formação de professores que atuam com crianças em ambientes formais e não formais.

O livro "Jogos e Brincadeiras: tempos, espaços e diversidade" reúne autores com pesquisas que retratam o tema do jogo, brinquedo e brincadeira - suas características, conceitos e dimensões -, dialogando com diferentes realidades. Apresenta um olhar para a criança que influi diretamente no processo pedagógico dos envolvidos com a educação de crianças pequenas em ambientes institucionais.

Um dos aspectos relevantes da obra diz respeito às abordagens sobre o brincar em diferentes culturas e períodos históricos, desde as brincadeiras à época da colonização portuguesa no Brasil, do povo Quilombola, até as narrativas orientais, com possibilidades de desenvolvimento desses tipos de jogos, brinquedos e brincadeiras em contextos variados na forma de projetos multiculturais. O tema abordado nesta obra resulta de trabalhos acadêmicos de estudantes de pós-graduação stricto sensu (FE-USP) e de outras investigações sobre a temática lúdica, coordenados pelas Professoras Tizuko Morshida Kishimoto (USP) e Maria Walburga dos Santos (UFSCar) e mostra-nos uma visão ampla do jogo, brinquedo e brincadeira numa perspectiva cultural, ampliando a compreensão sobre a atividade lúdica de crianças pequenas. O livro se fundamenta, tendo como eixo transversal os tempos, os espaços e a diversidade.

É organizado em dez capítulos e surpreende o leitor pelo foco em diferentes temas. Transpõe o jogo, o brincar e o brinquedo como festas, rituais, mitos, contos, narrativas, com situações vivenciadas em diversos contextos. Leitura imprescindível para a formação lúdica dos professores da educação infantil para que se conheça a importância do brincar no desenvolvimento e na aprendizagem da criança pequena em ambientes coletivos.

O primeiro texto, "Pesquisa sobre brinquedo no início do século XX", de Tizuko Morchida Kishimoto, apresenta resultados de duas pesquisas sobre preferências de brinquedos de crianças do ensino primário no início do século XX, em Belo Horizonte e em São Paulo e mostra a escassez de pesquisas com crianças de escolas públicas nesse campo, com o objetivo de estudar o lúdico, a compreensão dos contextos políticos e educacionais e o diagnóstico dos brinquedos preferidos por crianças do ensino primário à época, além da compreensão do papel do brincar e as teorizações adotadas nesse período histórico. Segundo Tanuri (2000), à época, havia uma diferenciação nos cursos das escolas de formação: "por um lado, houve expansão de escolas normais de nível menos elevado, compatível às peculiaridades regionais e, por 
outro, a consolidação das escolas normais responsáveis pela preparação docente para o ensino primário" (TANURI, 2000, p. 71). O objetivo das duas investigações relaciona-se com as Políticas Públicas dos respectivos Estados, o de enfatizar a formação prática dos futuros profissionais, com a oferta de subsídios sobre o conhecimento e as necessidades da criança, com ênfase na dimensão lúdica. Há a necessidade de mudança e a superação do modelo de escola tradicional que prevalece até hoje. Segundo as pesquisadoras, a preocupação com a diversidade dos contextos familiares, a necessidade da escuta da criança, seus impactos no brincar, permitem observar a correlação do brincar com as características das famílias operárias de classes intermediárias e de profissionais liberais daquela época, revelando a preocupação com a diversidade social e cultural das famílias, as relações de gênero, a etnia e a dimensão lúdica.

No segundo texto, "Felicidade Guerreira: brincar no Quilombo", Maria Walburga dos Santos, no campo da História da Educação, articula dois temas que se inter-relacionam: a constituição dos Quilombos contemporâneos especificamente em Bombas (Vale do Ribeira em São Paulo) e a presença do lúdico e do brincar na referida comunidade, apresentando as formas de brincar que persistem ou emergem no cotidiano de seus habitantes e nas escolas. $\mathrm{O}$ artigo expõe a história dos Quilombos, dos Quilombolas e dos diferentes tipos de resistência ali presentes. São identificados os principais jogos e brincadeiras com situações lúdicas e enfoque nas narrativas, que junto às atividades lúdicas em geral, fazem interfaces com a memória da região com foco na permanência, preservação ou produção de cultura africana no Brasil e a constituição de novas formas de viver em terras americanas que seriam inspiradas no modo de viver africano.

O terceiro texto, "Jogos de tabuleiro: análise na perspectiva histórica", de autoria de Lila Cristina Guimarães Vanzella, apresenta critérios e pistas que permitem estudar e analisar jogos de tabuleiro em sua materialidade e imaterialidade, tomando-os como objetos da história, pois registram leituras de mundo e têm como ponto de partida a decifração dos modos de vida das sociedades. A autora define alguns conceitos de jogos e identifica suas características. Diferencia o jogo do brinquedo, porque exigem do jogador certas habilidades definidas por uma estrutura preexistente no próprio objeto e suas regras. Explicita a origem dos jogos, narrando uma fábula que ilustra as três concepções do jogo (inteligência, sorte, oportunismo), como objeto da cultura e suas perspectivas materiais e imateriais. Traz a religião presente no jogo e finaliza com os jogos de tabuleiro de percurso de base quadriculada. 
No capítulo "O lúdico na época de Anchieta", Maria Ephigênia de Andrade Cáceres Nogueira, apresenta estudo também de base histórica, sobre o universo lúdico infantil na época de José de Anchieta, evidenciando a carência de estudos sobre o tema, o que levou a investigar a atuação da Companhia de Jesus no Brasil, salientando a importância da cultura europeia católica no período do Renascimento e sua influência sobre a colonização portuguesa no Brasil que, por sua vez, herdou a concepção de criança da Europa Católica. Pela consulta a documentos da Companhia de Jesus, a autora descreve a influência da Igreja Católica sobre o conceito de criança, considerada à época, como um pequeno adulto, sem especificidade etária, em que as brincadeiras serviam como meio para as evangelizações com as músicas. $\mathrm{O}$ texto traz as concepções de jogo, brinquedo e brincadeira para aquele período histórico e explora os quadros de Van Cleef e Pieter Brueghel, que traziam dimensões de ludicidade e de imagens do corpo de crianças em espaços públicos, em todos os seus aspectos.

O capítulo intitulado "O brincar na formação inicial de pedagogos" traz as inquietações de Kishimoto relacionadas à formação lúdica de professores de educação infantil em 1984 quando foi criado o LABRIMP - Laboratório de Brinquedos e Materiais Pedagógicos - da Faculdade de Educação da Universidade de São Paulo, o que gerou intensos debates, procurando atender as demandas dos estudantes para estudos que contemplassem a infância. Tais propostas encontravam resistências institucionais pela persistência de um espírito cartesiano de base positivista na formação dos cursos de graduação. Para a autora, a compreensão do papel do educador de brincar junto com a criança, o conceito de infância e seu reflexo sobre a educação e o ensino, interferem no modo de educar. Nessa perspectiva, os saberes docentes são problematizados na atuação lúdica, salientando-se a integração entre teoria e prática propiciada pelo processo reflexivo, buscando-se articulação equilibrada sobre a reflexão no desenvolvimento da aprendizagem e na análise da realidade, revelando que tal processo formativo desenvolvido na FE-USP favoreceu a criação de um ambiente de aperfeiçoamento de diversas experiências docentes, sendo fundamental para a formação de professores a mediação e o incentivo à problematização teóricas e práticas.

O sexto texto trata do "Brincar: oportunidade lúdica nos tempos livres da criança", de Maria de Lourdes Gonçalvez e se inicia com uma constatação sobre a crescente institucionalização da criança e da necessidade de preservar o tempo livre como tempo de lazer. Com o objetivo de compreender e interpretar as práticas evidenciadas pelos diferentes atores sociais, aborda uma dimensão constitutiva do brincar e a importância da brincadeira para as crianças como veículo de aprendizagem e de socialização das culturas infantis no 
âmbito da educação informal e seu contexto de dinamização dos tempos livres da infância. Este estudo teve como objetivo dar respostas, compreender e interpretar as práticas evidenciadas pelos atores sociais. Problematiza sobre a negligência do direito ao brincar, o conceito de criança desprovida de saberes e a ausência de uma Pedagogia específica da infância nos ambientes institucionais em que as crianças circulam.

O tema - título do capítulo seguinte: "Brinquedos e Gênero na Educação Infantil", de Tânia Maria Cordeiro, se fundamenta em tese de doutorado datada de 2003 (na Universidade de São Paulo/USP) realizada em uma unidade de educação infantil no município de Niterói, no Rio de Janeiro. Tem como propósito identificar, numa perspectiva Foucaultiana, como as representações de gênero são produzidas, sendo destacados os brinquedos e as brincadeiras das crianças como um meio de socialização na faixa etária de 0 a 6 anos. A autora ressalta que essas concepções de gênero implicam em relações de poder e se inscrevem nos corpos e nas identidades, acrescentando como os currículos podem contribuir para a posição de submissão e de desvantagem econômica entre mulheres e homens. Investiga as escolhas de gênero feitas pelas crianças, que mais tarde podem induzir as escolhas de determinadas disciplinas, revelando a linha divisória que separa disciplinas escolares masculinas e femininas, o que pode reforçar processos de construção de identidades relacionadas ao mundo doméstico e que poderiam contribuir para a tendência de suas opções profissionais. Aborda a presença da indústria de brinquedos que exerce forte influência sobre as escolhas de brinquedo entre meninos e meninas, por meio de sua publicidade e nas escolhas dos adultos que os compram para as crianças. Nas observações feitas na pesquisa, destaca-se que as crianças brincam, geralmente, separadas por sexo, sobretudo quando há brinquedos (as relações de poder se instituindo). Ao final, a autora destaca a importância da desconstrução de representações de gênero que fomentem discriminações.

O oitavo tema - capítulo do livro intitulado "O lúdico e a emergência da Literacia em creche", de Graça Bandola Cardoso, retrata estudo realizado no Centro Comunitário ao Norte, de uma pequena localidade de Portugal, como pré-requisito para o doutoramento na Universidade do Minho (região de Braga - localizada na região Norte do país), no período de 2007 a 2012. Apresenta o contexto educativo a época, no qual imperava a visão da criança como uma pessoa a ser modelada ao adulto e à sua cultura. A pesquisa mostra os efeitos do brincar na emergência da literacia (sinônimo de letramento e/ou a capacidade de cada indivíduo compreender e usar a informação escrita). A instituição pesquisada caracterizava-se numa perspectiva tradicional de Educação e os professores aparentavam ter baixa expectativa 
sobre o brincar. O processo da pesquisa envolveu intervenção e implicou no aprofundamento de referências pedagógicas de raiz sócio-construtivista com atividades como brincar de ler e escrever para se criar hipóteses conceituais sobre a linguagem escrita. A partir de temas trazidos pelas crianças a autora sugere princípios básicos para o trabalho com crianças pequenas. Segundo a autora, o brincar com a escrita, o cuidado com o ambiente e as oportunidades pedagógicas ali criadas, propiciaram explorações, o desenvolvimento do pensamento, da imaginação e do fazer diferenciado das crianças.

O capítulo seguinte aborda o "Mukashi Banashi: narrativas antigas Japonesas e a transmissão cultural”, de autoria de Maria do Carmo Monteiro Kobayashi e Letícia Sayuri Morinishi e conduzem o leitor ao contexto da literatura infantil ocidental e oriental, com o foco nas narrativas antigas Japonesas as "Mukashi Banashi”, apurando a transmissão dessas narrativas entre membros de famílias Nikkei, radicada em Mogi das Cruzes (cidade paulista). Kobayashi e Morinishi fazem uma cronologia dessa literatura infantil e suas influências póssegunda guerra mundial. Analisam a procedência, a idade e a chegada ao país dos membros da família Nikkei, demonstrando as participações de cada sexo, as histórias ouvidas e quem contava as narrativas japonesas, sobre suas formas de transmissão para as crianças. Lamentase a perda gradual da memória desse grupo social, de suas histórias infantis, seu legado para as novas gerações. De acordo com Bosi (1994), a memória dos mais velhos tem a dimensão de atualizar, para as novas gerações, as lembranças de um passado que se reitera no presente e se projeta no futuro.

O texto final problematiza um estudo sobre as "Classificações de Objetos lúdicos: sistema COL na Brinquedoteca, de Gilles Henrique Tavares de Azevedo", apresentando o funcionamento de algumas classificações de objetos lúdicos e como uma classificação específica como o sistema COL (Classement des Objets Ludiques) é utilizado na maioria das Brinquedotecas (operacionalizado na Brinquedoteca da Faculdade de Educação da USP, em seu processo de classificar, organizar e recuperar jogos e brinquedos). Questiona sobre o uso e a eficiência desse sistema na FE-USP. Apresenta, ainda, classificações dos objetos lúdicos ao longo da história do século XVI com quadros explicativos, demonstrando a eficiência do programa por meio de testes que tentam recuperar a posição dos jogos informada pelo código ou nome do jogo. Aponta a importância da existência de um sistema de classificação, porque além da manutenção e da organização do ambiente da Brinquedoteca, permite a exploração das potencialidades de cada jogo e a sua utilização. 
Os capítulos apresentados na obra levam o leitor a refletir sobre como o brincar, o jogo e a dimensão lúdica, em geral, estão sendo tematizados em ambientes educativos, destacando a importância de se conhecer a história das atividades lúdicas e a importância na formação de professores.

A imagem da criança se modificou historicamente, o que nos faz pensar nas semelhanças e diferenças, se seria ainda um adulto em miniatura e no uso instrumental dos jogos, brinquedos e brincadeiras, sendo que o direito da criança de ser livre, de brincar e se divertir deve ser preservado em todos os tempos. Ocorre que as diferentes formas de cultura escolar, muitas vezes, negligenciam esse direito em prol, por exemplo, da alfabetização precoce, da preparação para níveis escolares subsequentes ou ainda, da preparação para o "mundo do trabalho", com rotinas escolares que não privilegiam a escuta e as escolhas das crianças.

Nesse sentido, cabe assinalar a importância de pesquisas feitas com crianças (e não sobre crianças) especialmente sobre suas narrativas e percepções acerca dos ambientes escolares, que apresentam perspectivas enigmáticas para os adultos-educadores e que afetam as suas relações entre o brincar e o aprender, o fazer ou não fazer amigos, o ser ou não ser criança, trazendo elementos significativos para o entendimento das formas como elas se constituem ou não sujeitos de direitos (PASSEGGI et al, 2014).

Nos tempos atuais de perda de direitos que o país atravessa e de encurtamento da infância pelas sucessivas iniciativas governamentais que insistem em não reconhecer as características próprias da infância, em que a dimensão lúdica é fator preponderante e pelo crescente consumismo infantil (GOMES; VENÂNCIO, 2013), o direito à educação e ao brincar, garantidos legalmente para as crianças pequenas necessita ser reafirmado e assegurado. As relações de poder implicadas nos brinquedos escolhidos e subjetivamente indicados a meninos e meninas, apontam para uma sociedade de submissão, sobretudo da mulher, o que não contribui para a construção de uma sociedade mais equânime, justa e democrática.

O livro colabora, assim, para que educadores em geral se apropriem de conceitoschave nessa área, de modo a refletir e problematizar sobre teorias e práticas pedagógicas e, sobretudo, sobre as relações imbricadas sobre criança e infância(s). 


\section{Referências}

BOSI, E. Memória e sociedade: lembranças de velhos. São Paulo; Companhia das letras, 1994.

GOMES, M. de O.; VENÂNCIO, N. Criança, infância e consumo: um olhar para a aprendizagem profissional da docência na educação infantil. Revista Eletrônica Pesquiseduca, Santos, v. 5, n. 9, p. 112-124, jan./jul. 2013. Disponível em: http://periodicos.unisantos.br/index.php/pesquiseduca/article/view/180/pdf. Acesso em: 12 jul. 2018.

PASSEGGI et al. Narrativas de crianças sobre as escolas da infância: cenários e desafios da pesquisa (auto) biográfica. Educação, Santa Maria, v. 39, n. 1, p. 85-104, jan./abr. 2014. DOI: http://dx.doi.org/10.5902/1984644411345. Disponível em:

https://periodicos.ufsm.br/reveducacao/article/view/11345/pdf; Acesso em: 10 jan. 2019.

TANURI, L. M. História da formação de professores. Revista Brasileira de Educação. n. 14, p. 61-88, mai./ago. 2000. Disponível em: http://www.scielo.br/pdf/rbedu/n14/n14a05; Acesso em 10 jan. 2019.

Recebido em: 13/01/2019

Aprovado para publicação em: 02/04/2019

Publicado em: 30/08/2019 